\title{
The Occurrence of Muramic Acid in Wax D Preparations of Mycobacteria
}

\author{
By D. E. S. STEWART-TULL AND R. G. WHITE \\ The Department of Bacteriology, The London Hospital, E. 1
}

(Received 29 May 1963)

\begin{abstract}
SUMMARY
Acid hydrolysates of wax $\mathbf{D}$ preparations from human and bovine strains of Mycobacterium tuberculosis were examined by paper chromatography. The amino acids detected in human wax D preparations were alanine, glutamic acid and meso- $\alpha, \epsilon$-diaminopimelic acid. In general, amino acids were not found in bovine wax D preparations. Muramic acid was found in all wax $\mathbf{D}$ preparations from human strains of mycobacteria but was not detected in wax $D$ preparations from bovine strains. The presence of this typical cell-wall component, as well as the foregoing amino acids, suggests a close relationship between wax $D$ and the cell-wall mucocomplex. The role of muramic acid in the structure of wax $\mathbf{D}$ of human strains of mycobacteria is discussed.
\end{abstract}

\section{INTRODUCTION}

The chemical analogy between the water-soluble moiety of wax $\mathbf{D}$ and the cell wall of mycobacteria has been suggested (White, Bernstock, Johns \& Lederer, 1958; Asselineau \& Lederer, 1960; Lederer, 1961 $a, b)$. The present work was undertaken to determine whether the wax $\mathbf{D}$ fraction of mycobacteria represents part of their cell-wall mucocomplex. Following the classical studies on the extraction of lipids from tubercle bacilli by Anderson (1927, 1929) and Anderson \& Roberts $(1930 a, b)$, Aebi, Asselineau \& Lederer (1953) isolated wax D of tubercle bacilli from the chloroform-soluble waxes. Wax $D$ prepared from bovine or saprophytic strains of mycobacteria consists in general of mycolic acids esterified to a polysaccharide containing arabinose, galactose and mannose, but without a peptide (Lederer, 1960; Jollès, Samour \& Lederer, 1962). Asselineau, Buc, Jollès \& Lederer (1958) and Jollès et al. (1962) showed that a water-soluble peptido-polysaccharide of Wax D preparations from human strains of mycobacteria contained a heptapeptide composed of three amino acids (alanine, glutamic acid, $\alpha, \epsilon$-diaminopimelic acid), hexosamines (glucosamine and a smaller amount of galactosamine), and sugars (arabinose, galactose, mannose). Muramic acid was not found although it was 'not excluded that a little muramic acid may be present'.

Muramic acid is an important specific component of the bacterial cell-wall mucopeptide. Salton (1960) showed that the function of muramic acid is to link peptides to other sugars or sugar residues through an amide bond at the carboxyl group of muramic acid. Since wax D preparations from human strains of mycobacteria possess a peptide, hexosamines and a polysaccharide, the demonstration of muramic acid would be of interest in establishing a relation between the wax $\mathbf{D}$ 
of mycobacteria and their cell walls. The main purpose of the present work was to determine whether muramic acid was present in wax $\mathbf{D}$ preparations from mycobacteria.

\section{METHODS}

Strains of mycobacteria used. Strain ' $\mathrm{C}$ ' Mycobacterium tuberculosis var. hominis was obtained from the Central Veterinary Laboratories, Weybridge. The strains used in the preparation of the wax fractions were $M$. tuberculosis strains Brévannes, Canetti, Test, BCG and Marmorek.

Chemical fractions of mycobacteria. All chemical fractions of mycobacteria were prepared by Professor E. Lederer (Laboratoire de Chimie biologique, Paris) as follows. Mycobacteria were cultivated for 4 weeks on Sauton medium, filtered off, washed with distilled water and extracted several times at room temperature with 5 vol. of a mixture of ethanol +ether $(1+1$, by vol.). After 2 weeks the organisms were filtered off ana re-extracted several times with chloroform. The pooled chloroform extracts were extracted with boiling acetone, the insoluble fraction remaining being crude wax $D$. This was purified by refluxing $2 \mathrm{~g}$. crude wax with $50 \mathrm{ml}$. acetone for $3 \mathrm{hr}$., the solvent was filtered off while still hot; after six such extractions the acetone dissolved no more substance. Preparations thus obtained are called purified wax $D$. Such preparations were obtained from three human strains and two bovine strains of mycobacteria.

Determination of the number of bacilli in wax $D$ preparations and in known weights of organisms. Amounts of dried bacilli of $M$. tuberculosis strain ' $C$ ' corresponding to the weights used for hydrolysis were prepared as a suspension in $\mathbf{0 . 5} \%$ Tween 80 and spread evenly over a $1.5 \mathrm{~cm}$. square marked out on a microscope slide. Each film was dried and stained by the Ziehl-Neelsen method. The bacilli in twenty random fields (area 0.0132 sq. $\mathrm{mm}$.) were counted and the number of bacilli per weight of whole organisms hydrolysed was calculated. The same procedure was carried out with $1 \mathrm{mg}$. samples of the wax $D$ preparations but the suspensions were prepared in chloroform.

Hydrolysis of wax $D$ preparations and whole organisms. Samples were hydrolysed in sealed tubes with $1 \mathrm{ml} .6 \mathrm{~N}-\mathrm{HCl}$ at $105^{\circ}$ for $18 \mathrm{hr}$. The hydrolysates were filtered to remove insoluble humins, evaporated to dryness over $\mathrm{P}_{2} \mathrm{O}_{5}$ and $\mathrm{KOH}$ in an Edwards centrifugal freeze-drying apparatus and finally resuspended in $\mathbf{0 . 2 5} \mathrm{ml}$. distilled water.

Chromatography. Amino acids were separated by two-dimensional chromatography on Whatman No. 1 paper $(10 \times 10$ in.) in Smith 10 in. Universal chromatanks (Shandon Scientific Co. Ltd., London). Two solvent systems were used: (a) butan-1-ol + acetic acid + water $(120+30+50$, by vol.) ascending, followed by water-saturated phenol in $\mathbf{N H}_{3}$ atmosphere ascending (Smith, 1960); $(b)$ the phenol + water solvent ascending followed by lutidine + water $(65+35$, by vol.) either descending or ascending (Cummins \& Harris, 1956). Each solvent was run for $17 \mathrm{hr}$. The chromatograms were dried and the spots located by dipping in ninhydrin in acetone $(0 \cdot 1 \%, \mathrm{w} / \mathrm{v})$.

Stereoisomers of $\alpha, \epsilon$-diaminopimelic acid $(\boldsymbol{D A P})$. These were identified by chromatography on Whatman No. 1 paper $(45 \times 15 \mathrm{~cm}$.) with methanol + water $+10 \mathrm{~N}-\mathrm{HCl}$ + pyridine $(80+17 \cdot 5+2 \cdot 5+10$, by vol. $)$ ascending. The spots were located by 


\section{Muramic acid in wax $D$ of mycobacteria}

dipping in ninhydrin in acetone $(0 \cdot 1 \%, \mathrm{w} / \mathrm{v})$ and heating at $100^{\circ}$ for $2 \mathrm{~min}$. (Rhuland, Work, Denman \& Hoare, 1955; Hoare \& Work, 1957). DAP spots were characteristically olive-green at first, fading to a permanent yellow colour, in contrast to the purple colour of the other amino acids.

Hexosamines. These were identified by one-dimensional descending chromatography on Whatman No. 3 MM paper $(57 \times 23 \mathrm{~cm}$.) or Schleicher $2043 \mathrm{~b}$ paper. The solvent used was a modification of the one described by Bourillon \& Michon (1959), butan-1-ol + pyridine + water containing $0 \cdot 4 \%$ glacial acetic acid $(60+35+$ 25 , by vol.), and was allowed to descend for $36 \mathrm{hr}$, after which the chromatograms were dried and the hexosamines located with ninhydrin or with the modified Elson \& Morgan reaction of Partridge (1948). With the latter method, glucosamine and galactosamine appeared as pink spots and muramic acid as a salmon-pink spot.

\section{RESULTS}

The amino acids and hexosamines detected in the wax fractions are shown in Table 1. The hydrolysates of waxes from human strains of mycobacteria contained alanine, glutamic acid and $\alpha, \epsilon$-diaminopimelic acid as major components, with traces of aspartic acid, serine or glycine in some cases. Amino acids were not detected in the hydrolysates prepared from wax fractions of bovine strains of mycobacteria, with the exception of specimen WL 44, the wax $D$ fraction with a high melting point of strain Marmorek, which showed weak spots for alanine, glutamic acid, aspartic acid and glycine. Chromatograms of whole bacilli of Mycobacterium tuberculosis strain ' $\mathrm{C}$ ' revealed thirteen amino acids, with an increase in the intensity of spots proportional to the weight of bacilli hydrolysed. DAP was not present in the same proportion as either alanine or glutamic acid because the former is present only in the cell wall, while the other amino acids are also cytoplasmic components. In all cases where DAP was detected the chromatographic spot corresponded with that of the DD- or meso- forms, but was assumed to be meso-DAP after the findings of Work (1951). Bacterial counts showed that $85 \times 10^{5}$ whole bacilli were required to give detectable DAP on a chromatogram.

Glucosamine, galactosamine and muramic acid were located on the one-dimensional chromatograms by Partridge's method. Muramic acid was found in eleven wax D preparations from human strains of mycobacteria. Hexosamines were not found in the wax $D$ fractions of bovine strains with the exception of WL 44, the wax D preparation from strain Marmorek, in which glucosamine and galactosamine were detected. During the preparation of this paper it was learned that Professor E. Lederer and Dr P. Jollès (personal communication) had also found muramic acid in wax $\mathbf{D}$ preparations by column chromatography.

Since most wax D preparations are contaminated with small amounts of whole mycobacteria, the possibility that this impurity accounted for the presence of muramic acid was considered. This seemed unlikely since the experiments with whole $M$. tuberculosis organisms showed that $26 \times 10^{9}$ bacilli had to be hydrolysed to yield a faint spot for muramic acid on a chromatogram, and at this concentration strong spots for valine, leucine, isoleucine, threonine and lysine were also apparent. In the human mycobacteria wax $\mathrm{D}$ preparations muramic acid was detected without the spots for these latter amino acids. Secondly, bacterial counts showed that too 
Galactosamine $\quad \cdot+1 \cdot+1+++\cdot++\mid \begin{array}{llll}\mid & 1 & 1 & 1\end{array}$

Glucosamine $\quad++1+1+++++++\quad 1 \quad 1 \quad 1+11$

Muramic acid $\quad+1+++1+++++1++\quad \begin{array}{lllll}1 & 1 & 1 & 1 & 1\end{array}$

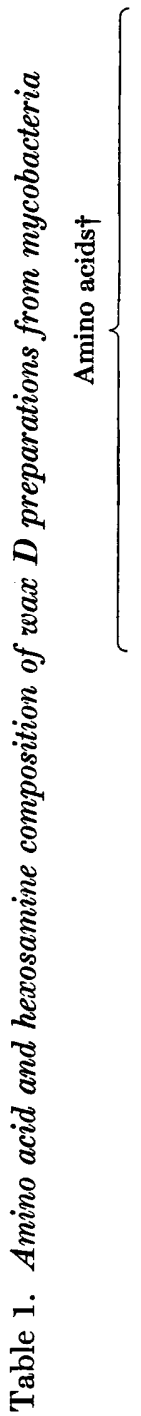

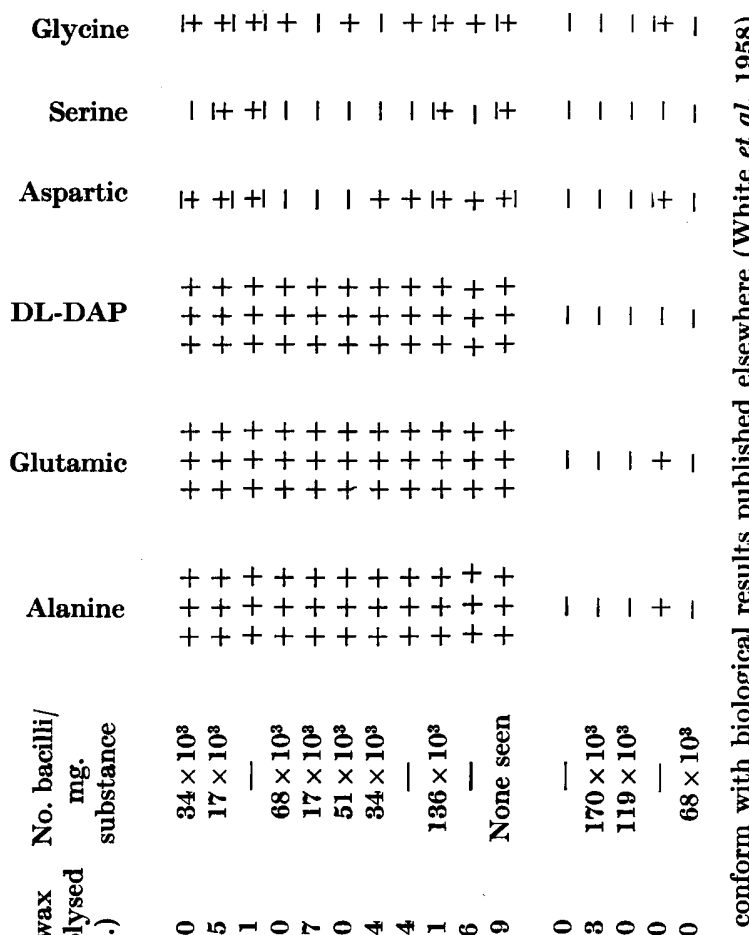

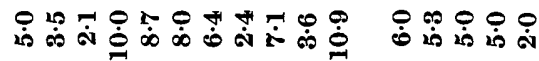


few bacilli were present in the wax $D$ fractions to yield a detectable spot for muramic acid, and although the contamination of bovine wax D preparations with bacilli was as great as that for human wax $\mathbf{D}$ preparations, neither amino acids nor hexosamines were detected.

\section{DISCUSSION}

The presence of muramic acid in wax $D$ preparations from human mycobacterial strains as an integral component suggests a close relation with the cell wall of the organism. Analyses of mycobacterial cell walls (Cummins \& Harris, 1958) have shown the presence of amino acids (alanine, glutamic acid, meso-DAP), hexosamines (glucosamine, muramic acid) and sugars (arabinose, galactose). Thus the demonstration of muramic acid together with alanine, glutamic acid and mesoDAP in wax D preparations supports the hypothesis that these waxes are integral components of the cell-wall mucocomplex. Further support for this hypothesis comes from the finding (Jollès et al. 1962; White, Jollès, Samour \& Lederer, 1964) that the molecular proportions of these amino acids in wax $\mathbf{D}$ preparations are within the ranges described for the cell walls of mycobacteria (Belknap, Camien \& Dunn, 1961).

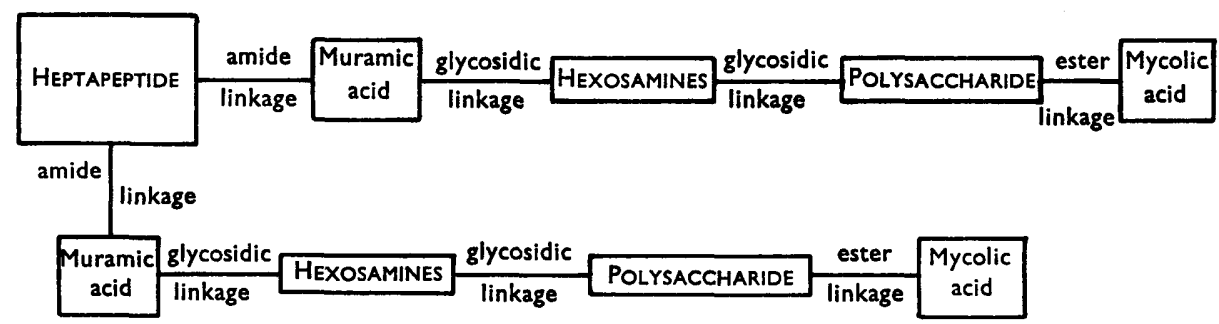

Fig. 1. Incorporation of muramic acid into the hypothetical structure of wax D of human strains of mycobacteria.

Asselineau et al. (1958) proposed a structure for the wax D of human strains of Mycobacterium tuberculosis in which hexosamines were established as the intermediates between the heptapeptide and the polysaccharide. Jollès, Cros \& Lederer (1960) postulated that the heptapeptide and polysaccharide were linked by a bond between a carboxyl group of meso-DAP and galactosamine, and a glycosidic linkage between galactosamine and arabinose. Asselineau et al. (1958) showed that there were no free amino groups in the heptapeptide. However the structure of Jollès et al. (1962) incorporating galactosamine as the intermediate hexosamine, would presumably leave two free amino groups. It is possible that the role of muramic acid as a structural component of wax $D$ could be to link the heptapeptide to sugars or sugar residues as it does in the cell wall. If there are no free amino groups it is conceivable that muramic acid is linked to each molecule of meso-DAP and a possible structure for wax $D$ of human strains of $M$. tuberculosis might be as shown in Fig. 1.

The relationship of the wax $\mathbf{D}$ of bovine mycobacterial strains to the cell-wall mucocomplex requires further explanation. Recently it has been suggested that the cell-wall mucocomplex may be composed of a mixture of polymers of relatively 
high and different molecular weights (Rogers, 1963). The wax D of mycobacteria may also consist of a mixture of different sized polymers. On the basis of the structure proposed above the polymer building-blocks would be: $(A)$ muramic acid +heptapeptide, $(B) n$-acetylgalactosamine $+n$-acetylglucosamine, and $(C)$ polysaccharide + mycolic acid. On the basis of the results of the composition of the waxes, wax $\mathrm{D}$ of human strains of $M$. tuberculosis would contain the buildingblocks $A, B$ and $C$ linked together. The high melting point fraction of the bovine wax D preparation, WL 44, may contain polymer building-blocks $B$ and $C$ linked together and the wax $\mathrm{D}$ of bovine strains of $M$. tuberculosis could be polymer building-block $\boldsymbol{C}$.

Our thanks are due to Dr Elizabeth Work and to Dr H. J. Rogers for supplying samples of muramic acid, and to Professor E. Lederer for supplying all preparations of wax $\mathrm{D}$ used in this investigation. This investigation was supported (in part) by grant No. E 4554 from the National Institute of Allergy and Infectious Diseases, the United States Public Health Service.

\section{REFERENCES}

Aebi, A., Assemineau, J. \& Lederer, E. (1953). Sur les lipides de la souche humaine 'Brévannes' de Mycobacterium tuberculosis. Bull. Soc. Chim. biol., Paris, 35, 661.

Anderson, R. J. (1927). The separation of lipoid fractions from tubercle bacilli. J. biol. Chem. 74, 525.

Anderson, R. J. (1929). The chemistry of the lipoids of tubercle bacilli: IV. Concerning the so-called tubercle bacilli wax. Analysis of the purified wax. J. biol. Chem. 83, 505.

Anderson, R. J. \& Roberts, E. G. $(1930 a)$. Chemistry of the lipoids of tubercle bacilli : separation of lipoid fractions from avian tubercle bacilli. J. biol. Chem. 85, 509 .

Anderson, R. J. \& Roberts, E. G. (1930b). Chemistry of the lipoids of tubercle bacilli: separation of lipoid fractions from bovine tubercle bacilli. J. biol. Chem. 85, 529 .

Asselineau, J., Buc, H., Jollès, P. \& Lederer, E. (1958). Sur la structure chimique d'une fraction peptido-glycolipidique (cire $\mathrm{D}$ ) isolée de Mycobacterium tuberculosis var. hominis. Bull. Soc. Chim. biol., Paris, 40, 1953.

Asselineau, J. \& Lederer, E. (1960). Chemistry and metabolism of bacterial lipides. Lipide Metabolism. Ed. by K. Bloch, pp. 356-358. New York: Wiley.

Belknap, D. R., Cammen, M. N. \& Dunn, M. S. (1961). Amino acid composition of mycobacterial cell walls. Proc. Soc. exp. Biol., N.Y. 107, 289.

Bourillon, R. \& Michon, J. (1959). Résolution et détermination quantitative par chromatographie sur papier des glucides liés aux protéines. Bull. Soc. Chim. biol., Paris, 41, 267.

Cummins, C. S. \& Harris, H. (1956). The chemical composition of the cell wall in some Gram positive bacteria and its possible value as a taxonomic character. J.gen. Microbiol. 14, 583 .

Cummins, C. S. \& Harris, H. (1958). Studies on the cell wall composition and taxonomy of actinomycetales and related groups. J. gen. Microbiol. 18, 173.

HoAre, D. S. \& Work, E. (1957). The stereoisomers of $\alpha, \epsilon$-diaminopimelic acid. Biochem. J. 65, 441.

Jollès, P., Nguyen-Trung-Luong-Cros, H. \& Lederer, E. (1960). Sur la structure chimique de la partie peptidique de la cire $\mathbf{D}$ d'une souche humaine de $M$. tuberculosis. Biochim. biophys. Acta, 43, 559.

Jollìs, P., Samour, D. \& Lederer, E. (1962). Analytical studies on Wax D, a macromolecular peptidoglycolipid fraction from human strains of Mycobacterium tuberculosis. Arch. Biochem. Suppl. 1, 283.

LeDerer, E. (1960). Lipides des mycobactéries et tuberculose. Farmaco, 15, 44. 
LEDERER, E. $(1961 a)$. Chemistry and biochemistry of some biologically active lipids. Pure appl. Chem. 2, 587.

LEDERER, E. (1961 b). Glycolipids of acid-fast bacteria. Advanc. Carbohyd. Chem. 16, 207.

Partridge, S. M. (1948). Filter-paper partition chromatography of sugars. I. General description and application to the qualitative analysis of sugars in apple juice, egg-white and foetal blood of sheep. Biochem. J. 42, 238.

Rhuland, L. E., Work, E., Denman, R. F. \& Hoare, D. S. (1955). The behaviour of the isomers of DAP on paper chromatograms. J. Amer. chem. Soc. 77, 4844.

Rogers, H. J. (1963). The surface structures of bacteria. Symp. Biochem. Soc. 22, 55.

SALton, M. R. J. (1960). Microbial Cell Walls. Ciba Lectures in Microbial Biochemistry. New York: Wiley.

SмIтн, I. (1960). Chromatographic and Electrophoretic Techniques, vol. I. London: Heinemann.

White, R. G., Bernstock, L., Johns, R. G. S. \& Lederer, E. (1958). The influence of components of $M$. tuberculosis and other mycobacteria upon antibody production to ovalbumin. Immunology, 1, 54.

White, R. G., Jollès, P., SAmour, D. \& Lederer, E. (1964). Correlation of adjuvant activity and chemical structure of wax $D$ fractions of mycobacteria. Immunology, 7 , (in the Press).

Work, E. (1951). The isolation of $\alpha, \epsilon$-diaminopimelic acid from Corynebacterium diphtheriae and Mycobacterium tuberculosis. Biochem. J. 49, 17. 